\title{
The Relation of Polyphenoloxidase in Leaf Extracts to the Instability of Cucumber Mosaic and Other Plant Viruses
}

\author{
By B. D. HARRISON AND W. S. PIERPOINT \\ Rothamsted Experimental Station, Harpenden, Hertfordshire
}

(Received 15 March 1963)

\begin{abstract}
SUMMARY
Extracts made with buffered sodium diethyldithiocarbamate (DIECA) or potassium ethylxanthate from tobacco leaves infected with cucumber mosaic virus (CMV) were 5-500 times more infective than those made in buffer alone, or in buffer containing three other metal chelators which did not prevent the extracts going brown. DIECA preserved infectivity slightly better than did potassium ethylxanthate; both prevented browning equally. With DIECA in the extraction fluid, infectivity was not increased by other substances that enabled mitochondrial enzyme systems to be removed intact. CMV was inactivated by leaf polyphenols only when these were being oxidized. Oxidized polyphenols from virus-free leaves did not inactivate CMV when added together with copper, whereas deproteinized extracts of leaves crushed in an atmosphere of nitrogen did. When copper and chlorogenic acid, the main polyphenol in tobacco leaves, were added to infective extracts that contained polyphenoloxidase, the chlorogenic acid was oxidized and CMV was inactivated. A tobacco necrosis virus was slightly inactivated by incubating leaf extracts with chlorogenic acid and copper, but four other viruses were not. The tobacco necrosis virus was also the only one of these five to be at all stabilized by DIECA in the extraction fluid. The reported instability of some other plant viruses in leaf sap may mean that they also are susceptible to inactivation by polyphenoloxidase systems.
\end{abstract}

\section{INTRODUCTION}

During their extraction from leaves plant viruses are exposed to enzymes and the products of enzyme reactions. The ease with which viruses can be purified probably depends on their resistance to these systems. Some of the enzymes involved in virus-inactivating systems may be contained in subcellular organelles (Bawden \& Pirie, 1957). We therefore examined whether a labile virus, cucumber mosaic, could be stabilized by making extracts from leaves by a method that preserves the integrity of chloroplasts and mitochondria, and permits their removal. When infected tobacco leaves were crushed in a medium containing 2-amino-2-hydroxymethylpropane1,3-diol (tris) buffer, sucrose, ethylenediaminetetra-acetate (EDTA), citrate and phosphate, moderately to highly infective preparations were obtained, and $\mathbf{8 0 - 9 0 \%}$ of their infectivity was retained after the chloroplasts and mitochondria were removed by centrifugation. When sodium diethyldithiocarbamate (DIECA) was added to this extraction medium, to prevent browning of the leaf extracts, the infectivity was still greater. Indeed, when DIECA was used, most of the other components of the extraction medium proved to be unnecessary. In this paper we describe experiments made to investigate the effect of DIECA. 


\section{METHODS}

Viruses and plants. A derivative of Price's cucumber yellow mosaic virus was used unless otherwise stated; a strain from Britain that produces a green mosaic in systemically infected leaves of tobacco was used in some experiments. Both strains were cultured in tobacco (Nicotiana tabacum var. Xanthi-nc), and systemically infected leaves were used as source of virus. Infectivity was assayed by counting the local lesions produced in inoculated half-leaves of French bean (Phaseolus vulgaris var. Prince) or whole leaves of Chenopodium amaranticolor. C. amaranticolor gave less accurate results than French bean and was used only in summer, when local lesions do not develop on French bean (Bhargava, 1951). Tobacco mosaic virus was obtained from systemically infected leaves of Java tobacco and assayed in Xanthi tobacco. Lucerne mosaic and tomato black ring viruses were obtained from systemically infected leaves of Xanthi tobacco, tobacco necrosis ' $b$ ' virus from inoculated leaves of Xanthi tobacco, and carnation ringspot virus from inoculated leaves of French bean; tomato black ring virus was assayed in Xanthi tobacco and the other three viruses in French bean. Inocula to be compared were distributed among the leaves or half-leaves of the assay plants so that each inoculum occurred equally often in equivalent positions. Superfloss Celite (JohnsManville Ltd.) was added to all inocula to increase the number of lesions. The plants were grown in insect-proof glasshouses in which the temperature averaged $18^{\circ}$ but in summer sometimes exceeded $25^{\circ}$.

Preparation of leaf extracts. After removing the midribs, about $10 \mathrm{~g}$. of leaf-blade tissue from plants infected with any of the viruses was cut into strips and ground in a chilled mortar containing the extraction fluid (usually $5 \mathrm{ml} . / \mathrm{g}$. leaf) and about $5 \mathrm{~g}$. acid-washed sand. The suspension was freed from sand and fibre by squeezing through two layers of butter muslin, and the filtrate centrifuged at $10,000 \mathrm{rev} . / \mathrm{min}$. $(8000 \mathrm{~g})$ for $30 \mathrm{~min}$. The almost clear supernatant fluid was dialysed overnight in Visking tubing against two $4 \mathrm{l}$. lots of about $5 \mathrm{~mm}$-phosphate buffer $(\mathrm{pH} 7 \cdot 4)$. The whole procedure was done in a cold room at $\mathbf{0 - 5} 5^{\circ}$. Extraction fluids which contained either DIECA (10 $\mathrm{mm})$ or ascorbic acid $(10 \mathrm{~mm})$ were freshly made by dissolving these compounds in the appropriate buffer immediately before grinding the leaves.

Deproteinized extracts of tobacco leaves were made in three different ways. In the first, the leaf blades $(25 \mathrm{~g}$.) were crushed in an atmosphere of nitrogen by using the press described by Pirie (1961). The juice was collected in $40 \mathrm{ml}$. of phosphate

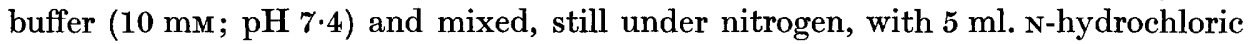
acid, then centrifuged at $8000 \mathrm{~g}$ for $30 \mathrm{~min}$. to remove the precipitate, the $\mathrm{pH}$ value adjusted to $\mathrm{pH} 7$ with $\mathrm{N}$-sodium hydroxide, and centrifuged again when a precipitate formed. In the second method, comparable extracts were made similarly, but in air.

The third method consisted of grinding the leaves in 3-4 times their own weight of $0.1 \mathrm{~N}$-hydrochloric acid through which nitrogen had been bubbled to remove oxygen. The extract was then adjusted to $\mathrm{pH} 5.5$ with $\mathrm{N}$-sodium hydroxide and the precipitate removed by centrifugation $(8000 \mathrm{~g}$ for $20 \mathrm{~min}$.). More sodium hydroxide was then added to the supernatant fluid to bring to $\mathrm{pH} 7$.

Buffers. Phosphate buffers were prepared from $\mathrm{M}-\mathrm{NaH}_{2} \mathrm{PO}_{4} \cdot \mathbf{2} \mathrm{H}_{2} \mathrm{O}$ by adding conc. $\mathrm{KOH}$ solution, and diluting to the specified molarity of phosphate. Tris 
buffers were similarly made from M-2-amino-2-hydroxymethylpropane-1:3 diol and $\mathrm{HCl}$, and were diluted to the specified molarity of the tris buffer.

Extraction, detection and estimation of polyphenols. Leaves (25 g.) were cut into small pieces and dropped immediately into $200 \mathrm{ml}$. boiling methanol. After $10 \mathrm{~min}$. the extract was filtered and the tissue re-extracted with $60 \mathrm{ml}$. boiling methanol. The two clear extracts were pooled, placed in a water bath at $40^{\circ}$, and evaporated to dryness with a water pump. The dry residue was then extracted overnight with a few ml. of water to which $0 \cdot 1 \mathrm{~N}$-sodium hydroxide was occasionally added to bring to between $\mathrm{pH} 6$ and 7 . Solutions containing polyphenols were spotted on to sheets of Whatman no. 1 filter paper and chromatograms developed for $4 \mathrm{hr}$. in either butan-1-ol + acetic acid + water $(6+1+1$ by vol.; Hillis \& Carle, 1962) or ethyl acetate + pyridine + water $(2+1+2$ by vol.; Weaving, 1958). After being air dried, the papers were examined in ultraviolet light before and after exposure to ammonia vapour, and were sprayed with either ferric chloride + potassium ferricyanide reagent (Barton, Evans \& Gardner, 1952) or a solution of sodium nitrite $(1 \%, \mathrm{w} / \mathrm{v})$ in acetic acid $(10 \%, \mathrm{v} / \mathrm{v})$ followed by N-sodium hydroxide (Roberts \& Wood, 1951).

Marker spots of chlorogenic acid, caffeic acid and rutin, three of the major polyphenol components of tobacco leaves, were added to most chromatograms. These substances were satisfactorily separated from each other in both solvents, although the spots tended to be rather streaked. They could be distinguished by their relative positions, by their appearance in ultraviolet light and by the colours they developed with the nitrite spray.

Rough estimations of the concentration of chlorogenic acid in leaf extracts were made from the appearance of chromatograms developed in the butanol solvent. For this purpose various volumes of extracts (usually 1, 2, 5, 7 and $10 \mu \mathrm{l}$.) were chromatographed on the same sheet of paper with similar volumes of a stock solution $(4 \mathrm{mg} . / \mathrm{ml}$.) of authentic chlorogenic acid, and the size and intensity of the chlorogenic acid spots were compared visually in ultraviolet light and again after spraying with ferric chloride+potassium ferricyanide solution. This comparison was expected to give only approximate values; two estimations done on one leaf extract on different days gave results that differed by $50 \%$.

\section{RESULTS}

\section{Effects of the extraction medium}

A medium previously used to extract mitochondria (Pierpoint, 1959) contained sucrose, phosphate, citrate, a chelating agent (EDTA), and was buffered at $\mathrm{pH} 7 \cdot 8$ with tris. Preparations obtained by crushing leaves in this medium were considerably more infective than water extracts. When the crude extracts were centrifuged at $1000 \mathrm{~g}$ for $7 \mathrm{~min}$. to remove chloroplasts and cell-wall fragments, centrifuged at $8000 \mathrm{~g}$ for $30 \mathrm{~min}$. to sediment mitochondria and then dialysed overnight against distilled water, the dialysis residue was only slightly less infective than the unclarified extract which had been stored at $2^{\circ}$. Only 5-10\% of the total infectivity was recovered from the chloroplast and mitochondrial fractions. The clarified extracts were brown, probably as the result of polyphenoloxidase activity (Shiroya, Shiroya \& Hattori, 1955). Browning was prevented and infectivity was greater when $10 \mathrm{~mm}$-DIECA, which is a metal-chelating agent and oxidase inhibitor, 
or ascorbic acid, was added to the extraction medium. Table 1 shows that when DIECA was used, ascorbic acid made no difference to infectivity and that some of the other components of the medium decreased it. In different experiments, extracts made with DIECA were 5-500 times more infective than comparable extracts made with buffer alone, and the difference was usually 10- to 20 -fold.

Table 1. Effect of the composition of the extraction medium on the infectivity of $C M V$ preparations from tobacco leaves

\begin{abstract}
Infected leaves were randomly divided into equal lots, and each lot ground in extraction medium $(8 \mathrm{ml} . / \mathrm{g}$. leaf) of the specified composition. The concentration of each component of the medium, when present, was: sucrose $0.4 \mathrm{M}$; tris buffer $0.2 \mathrm{M}$; citrate $20 \mathrm{~mm}$; EDTA, $5 \mathrm{~mm}$; potassium phosphate, ascorbic acid and DIECA, all $10 \mathrm{~mm}$. The $\mathrm{pH}$ of the medium was $7 \cdot 7$, and the extracts $7 \cdot 2$. The extracts were passed through muslin and centrifuged at $8000 \mathrm{~g}$ for $30 \mathrm{~min}$. before being dialysed against $5 \mathrm{~mm}$-phosphate $(\mathrm{pH} \mathrm{7.4)}$ and assayed for infectivity. The infectivity figures are total numbers of lesions in 8 half-leaves of French bean. Figures in parentheses are the dilutions of the extracts used as inocula. The green strain of CMV was used in Expt. 2, and the yellow strain in the other experiments.
\end{abstract}

Composition of extraction medium

\begin{tabular}{|c|c|c|c|c|c|c|c|c|}
\hline \multirow[b]{2}{*}{ Tris } & \multirow{2}{*}{\multicolumn{2}{|c|}{ DIECA $\begin{array}{c}\text { Ascorbic } \\
\text { acid }\end{array}$}} & \multirow[b]{2}{*}{ Sucrose } & \multirow{2}{*}{$\begin{array}{c}\text { EDTA, } \\
\text { citrate } \\
\text { and } \\
\text { phos- } \\
\text { phate }\end{array}$} & \multicolumn{4}{|c|}{ Infectivity of extract } \\
\hline & & & & & $\underset{(1 / 5)}{\text { Expt. } 1}$ & $\begin{array}{c}\text { Expt. } 2 \\
(1 / 5)\end{array}$ & $\begin{array}{c}\text { Expt. } 3 \\
(1 / 5)\end{array}$ & $\begin{array}{c}\text { Expt. } 4 \\
(\mathbf{1} / 10)\end{array}$ \\
\hline+ & - & - & + & + & 8 & 6 & . & . \\
\hline+ & - & + & + & + & 159 & 11 & . & . \\
\hline+ & + & - & + & + & 795 & 115 & . & . \\
\hline+ & + & + & + & + & 645 & 128 & 605 & 10 \\
\hline+ & + & + & - & + & • & . & 895 & 49 \\
\hline+ & + & + & + & - & . & . & 1970 & 892 \\
\hline+ & + & + & - & - & . & . & 3010 & 1100 \\
\hline
\end{tabular}

DIECA apparently prevents virus inactivation in leaf extracts and does not act by augmenting infection through an effect on the plant used for assay. Usually all but traces of DIECA were removed by dialysis before inoculation, and adding DIECA to $1 \mathrm{~mm}$ immediately before inoculation to extracts made either with or without DIECA did not affect infectivity. Nor does DIECA act by removing an inhibitor of infection. In general, the infectivity of mixtures of virus and inhibitor increased with dilution, whereas that of extracts made without DIECA did not. When DIECA was used, more infectivity was preserved when the extraction medium was at $\mathrm{pH} 7 \cdot 3$ to $8 \cdot 1$ than at higher or lower $\mathrm{pH}$ values (Table 2 ).

Table 3 compares the effects of DIECA with those of four other metal-chelating agents; potassium ethylxanthate, salicylaldoxime, 2,9-dimethyl-1,10-phenanthroline (neocuproine) and EDTA. These five agents all chelate copper but none is likely to be specific for it; the first three inhibit copper-containing enzymes such as some polyphenoloxidases, ascorbic oxidases (see Dawson \& Tarpley, 1951) and diamine oxidase (Mann, 1955; Hill \& Mann, 1962). Neither EDTA nor neocuproine inhibits diamine oxidase. DIECA and potassium ethylxanthate each prevented browning; the other three substances did not. Infectivity was preserved only by the substances which prevented browning; infectivity was preserved slightly better by DIECA than by potassium ethylxanthate. Although the latter two substances probably act 
by inhibiting a copper-containing enzyme, the results in Table 3 do not prove this. However, the failure of salicylaldoxime to prevent browning or to preserve infectivity does not necessarily mean that copper-containing enzymes are not involved. Albert, Rubbo, Goldacre \& Balfour (1947) found evidence that trace metals can be held at a biological surface in such a way that only chelating agents of appropriate architecture have access to them.

Table 2. Effect of $p H$ value on the stabilization of infectivity of leaf extracts by $D I E C A$

Forty g. of CMV-infected leaves were randomly separated into four equal lots and each lot was ground in about $100 \mathrm{ml}$. of DIECA (10 mM) dissolved in tris buffer $(0.2 \mathrm{mM})$ of various $\mathrm{pH}$ values. After squeezing through muslin, a sample of each extract was taken for $\mathrm{pH}$ measurement and the rest centrifuged at $8000 \mathrm{~g}$ for $30 \mathrm{~min}$. All extracts were then dialysed against $5 \mathrm{~mm}$-phosphate $\left(\mathrm{pH} \mathrm{7 \cdot 4}\right.$ ) for $6 \mathrm{hr}$. at $2^{\circ}$ before they were diluted and assayed for infectivity. The figures given are total numbers of lesions in 8 half-leaves of French bean.

$\begin{array}{ccc}\text { pH value } & \begin{array}{c}\text { Diluted } \\ 1 / 2\end{array} & \begin{array}{c}\text { Diluted } \\ 1 / 20\end{array} \\ 6 \cdot 4 & 580 & 86 \\ 7 \cdot 3 & 1490 & 490 \\ 8 \cdot 1 & 1590 & 550 \\ 9 \cdot 0 & 995 & 225\end{array}$

Table 3. Effect of chelators and other substances on the infectivity of leaf extracts

CMV-infected leaves were randomly divided into three or four equal lots and each lot ground in $0.2 \mathrm{M}$-tris $+\mathrm{HCl}$ buffer $(\mathrm{pH} 7 \cdot 8$ ) together with the substances specified. The extracts were then centrifuged and dialysed as usual before their infectivity was assayed. Figures are the total number of lesions in 8 half-leaves of French bean.

\begin{tabular}{|c|c|c|c|c|}
\hline \multirow[b]{2}{*}{ Substance added } & \multicolumn{4}{|c|}{ Infectivity } \\
\hline & Expt. 1 & Expt. 2 & Expt. 3 & Expt. 4 \\
\hline None & 101 & 20 & 38 & 105 \\
\hline DIECA (10 mM) & 680 & 780 & 462 & 1451 \\
\hline $\begin{array}{l}\text { DIECA }(10 \mathrm{~mm})+ \\
\text { polyvinylpyrrolidone }(2.5 \%, \mathrm{w} / \mathrm{v})\end{array}$ & 1175 & $\cdot$ & $\cdot$ & $\cdot$ \\
\hline Polyvinylpyrrolidone $(2.5 \%, \mathrm{w} / \mathrm{v})$ & 65 & - & - & . \\
\hline Salicylaldoxime (10 $\mathrm{mm})$ & . & 15 & . & . \\
\hline $\begin{array}{l}\text { 2,9-Dimethyl-1,10-phenanthroline } \\
\text { (10 mM) }\end{array}$ & . & 35 & . & . \\
\hline EDTA $(10 \mathrm{mM})$ & . & . & 80 & . \\
\hline$p$-Nitrophenol (10 mм) & . & . & 42 & . \\
\hline Potassium ethylxanthate $(10 \mathrm{~mm})$ & . & . & . & 758 \\
\hline
\end{tabular}

Attempts were also made to prevent the oxidation of phenolic substances in leaf extracts by using other types of inhibitors. When the extraction medium contained $p$-nitrophenol (a competitive inhibitor of some polyphenoloxidases; Bonner \& Wildman, 1946) or polyvinylpyrrolidone (a macromolecule that binds some phenolic compounds; Jones \& Hulme, 1961) instead of DIECA, infectivity was not preserved (Table 3). Browning was not prevented by polyvinylpyrrolidone, but the effect of $p$-nitrophenol was difficult to judge because it is itself yellowish brown. 


\title{
Effects of extracts of uninfected leaves on virus inactivation
}

The effect on infectivity of DIECA seemed likely to be caused by inhibiting polyphenoloxidase and so preventing virus from being inactivated either directly by the enzyme, or by substances formed from components of sap by enzyme action. Many infective preparations, dialysed to remove DIECA, became slightly brown immediately copper sulphate was added to them, but this had little effect on infectivity. The colour is probably caused by a complex formed between the copper and traces of DIECA left after dialysis. These results suggested either that the polyphenoloxidase was irreversibly inhibited, or that some other component of the

\section{Table 4. Effects of deproteinized extracts of uninfected leaves on infectivity of $\mathbf{C M V}$}

\begin{abstract}
Extracts made with tris + DIECA from CMV-infected leaves, and the three types of deproteinized extracts of uninfected leaves, were prepared as described under Methods. Samples of infective extract were incubated at room temperature for $2.5 \mathrm{hr}$. with the additions specified. The amounts of the additions differed in the three experiments, the range per $20 \mathrm{ml}$. or of final concentration being: infective extract 11-14 ml.; tris buffer (pH 7-4), 8.3-17 mM; copper sulphate 42-245 $\mu \mathrm{M}$; deproteinized extracts $4 \cdot 2-5 \cdot 9 \mathrm{ml}$. All samples were assayed for infectivity after dialysis overnight at $2^{\circ}$. Infectivity values are the numbers of lesions produced in 8 half-leaves of French bean. Figures in parentheses are the number of lesions produced by the same inocula diluted $1 / 5$ with water.
\end{abstract}

\begin{tabular}{|c|c|c|c|c|}
\hline \multirow{2}{*}{\multicolumn{2}{|c|}{ Additions }} & \multicolumn{3}{|c|}{ Infectivity } \\
\hline & & Expt. 1 & Expt. 2 & Expt. 3 \\
\hline (1) & None & 400 & $627(55)$ & $1000(83)$ \\
\hline (2) & Copper sulphate & 668 & $205(39)$ & 751 \\
\hline (3) & Deproteinized extract made in $\mathrm{N}_{2}$ & 708 & $333(59)$ & . \\
\hline (4) & As $(3)+$ copper sulphate & 84 & $17 \quad(2)$ & . \\
\hline (5) & Deproteinized extract made in air & 604 & $807(53)$ & . \\
\hline (6) & As $(5)+$ copper sulphate & 452 & $299(29)$ & . \\
\hline (7) & Deproteinized extract made in acid & . & . & 384 \\
\hline (8) & As $(7)+$ copper sulphate & . & . & $133(16)$ \\
\hline (9) & As (7), boiled + copper sulphate & . & . & 157 \\
\hline (10) & As (7), dialysed + copper sulphate & . & . & 567 \\
\hline
\end{tabular}

inactivating system was missing. To see whether uninfected tobacco leaves could supply a missing component, deproteinized leaf extracts were added with or without copper to infective preparations of CMV. CMV was inactivated in the presence of copper by deproteinized extracts made in nitrogen, but not by extracts made in air or when copper was omitted (Table 4). Deproteinized extracts made by crushing uninfected tobacco leaves in hydrochloric acid, which was later neutralized, also inactivated CMV only when copper was added. There was evidently too little copper in the deproteinized extracts to reactivate the enzyme. The active substance (or substances) supplied by these deproteinized extracts was lost on dialysis; it is stable to acid and to boiling, rapidly changes to an inactive form in leaf extracts made in air, and plays its part in the inactivating system only when accompanied by active enzyme (Table 4). Substrates of polyphenoloxidase have these properties.

\section{Polyphenols in extracts of tobacco leaves}

The oxidation of polyphenols by polyphenoloxidase appears to have many properties in common with the system that inactivates CMV in leaf extracts. The 
polyphenols in tobacco leaves were therefore examined. Chromatograms of methanolic extracts of healthy leaves and of $\mathrm{CMV}$-infected leaves showed one major migrating component, apparently an isomer of chlorogenic acid. It fluoresced blue in ultraviolet light, and gave a deep blue colour with the ferric chloride + potassium ferricyanide spray. It moved the same distance as the main component of commercial chlorogenic acid (L. Light and Co.) in both the solvents used and was not separated from chlorogenic acid when a mixture was chromatographed. It became pale yellow when chromatograms were exposed to ammonia vapour, and its fluorescence in ultraviolet light changed to the 'duck-egg green' characteristic of chlorogenic acid (Hulme, 1953). Like chlorogenic acid it went yellowish pink when sprayed with sodium nitrite + alkali (Roberts \& Wood, 1951).

Extracts of infected and healthy leaves each contained two other unidentified substances in smaller amount than chlorogenic acid. On the chromatograms one, which fluoresced blue in ultraviolet light and was stained blue with the ferric chloride + ferricyanide reagent, remained at the origin. The other was blue-green in ultraviolet light; it moved just behind chlorogenic acid in the butanol solvent, but scarcely moved from the origin in ethyl acetate + pyridine + water. There was a slight trace of a material with a mobility similar to caffeic acid in extracts of infected, but not of healthy, leaves. Rutin was not detected in extracts of either.

The amount of chlorogenic acid in a sample of healthy leaves was of the order of $0.05 \%$ of the fresh weight; in a comparable sample of CMV-infected leaves it was $0 \cdot 07-0 \cdot 11 \%$. A virus preparation made from these diseased leaves would therefore contain $\mathbf{0} \cdot \mathbf{2}-\mathbf{0} \cdot 4 \mathrm{~mm}$-chlorogenic acid. These values are less than reported for tobacco var. Xanthi leaves $(0 \cdot 26 \%)$ by Shiroya, Shiroya \& Hattori (1955), but their value probably refers to field-grown plants, which contain more chlorogenic acid and rutin than tobacco plants grown under glass (Frey-Wyssling \& Babler, 1957).

\section{Effect of chlorogenic acid on infectivity of leaf extracts}

When infective extracts, which were made with tris + DIECA, then dialysed and the dialysis residues incubated with chlorogenic acid and copper sulphate, the solutions became brown and much infectivity was lost. When copper was not added, chlorogenic acid had little effect on the infectivity of most extracts but the infectivity of a few decreased considerably. Many ways to eliminate this variability were tried using different batches of chlorogenic acid, cleaning all glassware with nitric acid, varying slightly the temperature and $\mathrm{pH}$ value of the infective extract during incubation with chlorogenic acid; but the variability remained. However, when copper was not added, chlorogenic acid inactivated CMV in more of the extracts made in the summer than in those made in winter.

After $2 \mathrm{hr}$. incubation at $20^{\circ}$ with chlorogenic acid + copper, the infectivity of extracts of leaves infected with CMV had usually decreased to a few \% of that of extracts incubated with copper or chlorogenic acid separately (Table 5). Tobacco mosaic, lucerne mosaic, tomato black ring and carnation ringspot, four viruses with very different properties, were not inactivated by this system. The ' $b$ ' culture of tobacco necrosis virus, which is the least stable of the tobacco necrosis viruses examined by Kassanis \& Nixon (1961), apparently was slightly inactivated (Table 5). The leaf extracts for these experiments were made in the usual way, with the aid of DIECA, and were dialysed before use. 
Further tests showed that adding DIECA to the extraction medium did not increase the infectivity of extracts of leaves containing any of the four viruses that were unaffected by the chlorogenic acid system, but that there was an increase with tobacco necrosis ' $b$ ' virus. For example, in one experiment an extract made with the aid of DIECA gave 724, 203 and 45 lesions in eight half-leaves of French bean when inoculated at dilutions of $1 / 5,1 / 50$ and 1/500, whereas an extract made without DIECA from the opposite halves of the same leaves gave 458, 117 and 13 lesions at the same three dilutions. Susceptibility of viruses to inactivation by the chlorogenic acid system therefore appears to be correlated with the ability of DIECA in the extraction medium to enhance infectivity.

\title{
Table 5. Inactivation of virus in leaf extracts on incubation with chlorogenic acid and copper
}

\begin{abstract}
Extracts of infected leaves were prepared in tris + DIECA solution and dialysed overnight at $2^{\circ}$. Samples $(5 \mathrm{ml}$.) were then added to tris buffer (final concentration about $50 \mathrm{~mm}$; pH 7), together with the substances specified below; the final volume was about $8 \mathrm{ml}$. The mixtures were kept at $21^{\circ}$ for $3 \mathrm{hr}$. (CMV) or for $2.5 \mathrm{hr}$. (tobacco necrosis virus) and then dialysed overnight against cold phosphate buffer ( $5 \mathrm{~mm} ; \mathrm{pH} \mathrm{7.4)}$ ). Infectivity was measured as the total number of lesions produced in 8 half-leaves of French bean. Figures in parentheses are the numbers produced by the same inocula diluted 1/10 with
\end{abstract} water.

\section{Additions}

(final concentration)

\section{None}

Copper sulphate $(0 \cdot 25 \mathrm{~mm})$

Chlorogenic acid $(2 \cdot 6 \mathrm{~mm})$

Copper sulphate $(0 \cdot 25 \mathrm{~mm})+$ chlorogenic acid (2.6 $\mathrm{mm})$

\begin{tabular}{|c|c|}
\hline \multicolumn{2}{|c|}{ Infectivity } \\
\hline $\begin{array}{l}\text { Cucumber } \\
\text { mosaic } \\
\text { virus }\end{array}$ & $\begin{array}{l}\text { Tobacco } \\
\text { necrosis } \\
\text { 'b' virus }\end{array}$ \\
\hline $1000(193$ & $228(67$ \\
\hline 955 & 273 \\
\hline 872 & 223 \\
\hline 35 & 152 \\
\hline
\end{tabular}

\section{DISCUSSION}

The simplest explanation of our results is that CMV is inactivated by the polyphenoloxidase systems in leaf extracts. Substances which prevented the extracts from becoming brown also protected the virus, whereas metal-chelators which did not prevent browning did not prevent virus inactivation. CMV is stable in extracts made with the aid of DIECA and then dialysed, because polyphenoloxidase is inhibited and because the polyphenol substrates diffused away during dialysis. The enzyme was reactivated by adding copper. Thus, when both copper and chlorogenic acid, the main polyphenol in tobacco sap, were added to virus preparations that contained the enzyme, chlorogenic acid was oxidized and CMV was inactivated. CMV is inactivated only while polyphenols are being oxidized. Thus, adding copper +extracts made in air from virus-free leaves to infective preparations, did not inactivate CMV because the polyphenols from the leaves were already oxidized. It is uncertain whether the polyphenols are oxidized by stages and only the intermediate products inactivate CMV, or whether the oxidized polyphenols react so quickly with proteins in extracts of virus-free leaves that they are no longer active when CMV is added.

Many of the virus-inactivating systems previously found in leaf extracts can be distinguished from the polyphenoloxidase system. In one type of system, the rapid 
inactivation of grapevine fanleaf virus in sap from grape leaves is caused by the acidity (pH 3-3.5; Dias, 1962), whereas the polyphenoloxidase system inactivates CMV at pH 7-8. In a second type, infectivity of some isolates of tobacco rattle and tobacco necrosis viruses is preserved only when leaves are crushed in watersaturated phenol or in pH 9 buffer (Sänger \& Brandenburg, 1961; Cadman, 1962; Babos \& Kassanis, 1962). Water extracts of the leaves are often less than $1 \%$ as infective as the extracts made by shaking with phenol. The phenol and pH 9 buffer seem likely to preserve infectivity by inactivating leaf ribonuclease and the other virus-inactivating enzymic systems described by Bawden \& Pirie (1959). Schlegel (1960) found that extracts from leaves infected with CMV were 1.5-7 times more infective when made with the aid of phenol and $1 \%$ tetrasodium pyrophosphate than when made with pyrophosphate alone. Whether the phenol preserved initially ribonuclease-sensitive CMV is not clear. However, we find that DIECA does not preserve the infectivity of the unstable tobacco necrosis virus, indicating that DIECA does not inhibit this inactivating system, which is inhibited by phenol.

A third type of inactivation, which occurs when leaf tannins come into contact with virus particles (Cadman, 1959), differs from the polyphenoloxidase system in that infectivity is preserved at $\mathrm{pH} 8$, a condition in which the tannin has little tendency to combine with virus. Another difference is in the range of viruses affected. Lucerne mosaic virus is permanently inactivated and tomato black ring virus is reversibly precipitated by the tannins, whereas neither was affected by the polyphenoloxidase system. Also, Cadman (1959) detected no tannins in tobacco leaves.

The polyphenoloxidase system has greater similarities to the inactivating system obtained by Bawden \& Pirie (1957) from leaves infected with tobacco necrosis virus. Neither affects tobacco mosaic virus; both occur in tobacco, need oxygen and involve a substance that is stable to boiling; and inactivation by both is partly prevented by ascorbate. Bawden \& Pirie (1957) inactivated tobacco necrosis virus in $20 \mathrm{hr}$. at $18^{\circ}$ and we found that tobacco necrosis virus was slightly affected in $2 \mathrm{hr}$. The two systems, however, seem to differ, because Bawden \& Pirie found most of their system was sedimented at $8000 \mathrm{~g}$, a procedure we use routinely to obtain infective supernatant fluids in which inactivation can be studied. With leaves infected with CMV, we find sediments obtained at $8000 \mathrm{~g}$ by the method of Bawden \& Pirie contain polyphenoloxidase, but little or no substrate. These sediments inactivated CMV in leaf extracts much more slowly than did chlorogenic acid+ copper. However, sediments from leaves infected with tobacco necrosis virus might inactivate CMV more rapidly.

DIECA has previously been used to stabilize other plant viruses. Hampton \& Fulton (1961) used it to preserve the infectivity of sour cherry necrotic ringspot virus in extracts of cucumber leaves. The virus was inactivated by fungal polyphenoloxidase when a substrate (catechol or tyrosine) was added. Similarly, Mink $\&$ Bancroft (1962) found that stable preparations of 'Tulare apple mosaic virus could be made with DIECA and cysteine $\mathrm{HCl}$, whereas in leaf sap the virus lost half its infectivity every $5 \mathrm{~min}$. (Yarwood, 1955). These two viruses and CMV seem to be particularly sensitive to inactivation by polyphenoloxidase systems. Tomato spotted wilt virus too is sensitive to oxidase systems. Inactivation in sap is greatly 
decreased by excluding oxygen, by keeping at $0^{\circ}$, or by adding reducing substances such as cysteine or sodium sulphite. Catechol inactivates the virus in sap kept in air, but not when sodium sulphite is also added (Best \& Samuel, 1936). Tobacco streak virus (Fulton, 1949) and rose mosaic virus (Fulton, 1952) also are stabilized by cysteine and sodium sulphite. These six viruses all soon inactivate in sap at room temperature, suggesting that in many instances the standard 'resistance to ageing test' measures the susceptibility of the virus to inactivation by polyphenoloxidase systems. It is possible that these systems also slowly inactivate moderately stable viruses.

\section{REFERENCES}

Albert, A., Rubbo, S. D., Goldacre, R. J. \& Balfour, B. G. (1947). The influence of chemical constitution on antibacterial activity. Part III. A study of 8-hydroxyquinoline (oxine) and related compounds. Brit. J. exp. Path. 28, 69.

Babos, P. \& Kassanis, B. (1962). Unstable variants of tobacco necrosis virus. Virology, 18, 206.

Barton, G. M., Evans, R. S. \& Gardner, J. A. F. (1952). Paper chromatography of phenolic substances. Nature, Lond. 170, 249.

Bawden, F. C. \& Pirie, N. W. (1957). A virus-inactivating system from tobacco leaves. J. gen. Microbiol. 16, 696.

Bawden, F. C. \& Pinie, N. W. (1959). The infectivity and inactivation of nucleic acid preparations from tobacco mosaic virus. J. gen. Microbiol. 21, 438.

Best, R. J. \& Samuel, G. (1936). The effect of various chemical treatments on the activity of the viruses of tomato spotted wilt and tobacco mosaic. Ann. appl. Biol. 23, 759 .

Bhargava, K. S. (1951). Some properties of four strains of cucumber mosaic virus. Ann. appl. Biol. 38, 377 .

Bonner, J. \& Wildman, S. G. (1946). Enzymatic mechanisms in the respiration of spinach leaves. Arch. Biochem. Biophys. 10, 497.

Cadman, C. H. (1959). Some properties of an inhibitor of virus infection from leaves of raspberry. J. gen. Microbiol. 20, 113.

Cadman, C. H. (1962). Evidence for association of tobacco rattle virus nucleic acid with a cell component. Nature, Lond. 193, 49.

Dawson, C. R. \& TARpley, W. B. (1951). Copper oxidases. In The Enzymes, vol. Ir, part 1, p. 454. Edited by J. B. Sumner and K. Myrbäck. New York: Academic Press.

DiAs, H. F. (1962). Sap-transmissible viruses of grapevines. Ph.D. Thesis: University of London.

Frey-Wyssling, A. \& Babler, S. (1957). Zur Biochemie des Gewächshaustabaks. Experientia, 13, 399.

Fulton, R. W. (1949). Virus concentration in plants acquiring tolerance to tobacco streak. Phytopathology, 39, 231.

Fulton, R. W. (1952). Mechanical transmission and properties of rose mosaic virus. Phytopathology, 42, 413.

Hampton, R. E. \& Fulton, R. W. (1961). The relation of polyphenol oxidase to instability in vitro of prune dwarf and sour cherry necrotic ringspot viruses. Virology, 13, 44.

Hill, J. M. \& ManN, P. J. G. (1962). The inhibition of pea-seedling diamine oxidase by chelating agents. Biochem. J. 85, 198.

Hrluss, W. E. \& Caris, A. (1962). The origin of the wood and bark polyphenols of Eucalyptus species. Biochem. J. 82, 435.

Hulme, A. C. (1953). The isolation of chlorogenic acid from the apple fruit. Biochem. J. $53,337$.

Jones, J. D. \& Hulme, A. C. (1961). Preparation of mitochondria from the peel of apples. Nature, Lond. 191, 370.

Kassanis, B. \& Nixon, H. L. (1961). Activation of one tobacco necrosis virus by another. J. gen. Microbiol. 25, 459. 
Mann, P. J. P. (1955). Purification and properties of the amine oxidase of pea seedlings. Biochem. J. 59, 609.

Mink, G. I. \& Bancroft, J. B. (1962). Purification and serology of Tulare apple mosaic virus. Nature, Lond. 194, 214.

Pierpoint, W. S. (1959). Mitochondrial preparations from the leaves of tobacco (Nicotiana tabacum). Biochem. J. 71, 518.

Pirie, N. W. (1961). The disintegration of soft tissues in the absence of air. J. agric. Engng Res. 6, 142.

Roberts, E. A. H. \& Wood, D. J. (1951). The polyphenols and amino acids of tobacco leaf. Arch. Biochem. Biophys. 33, 299.

Sänger, H. L. \& Brandenburg, E. (1961). Über die Gewinnung von infektiösem Presssaft aus 'Wintertyp' - Pflanzen des Tabak-Rattle-Virus durch Phenolextraktion. Naturwissenschaften, 48, 391.

Schlegel, D. E. (1960). Highly infectious phenol extracts from tobacco leaves infected with cucumber mosaic virus. Virology, 11, 329.

Shiroya, M., Shiroya, T. \& Hattori, S. (1955). Studies on the browning and blackening of plant tissues. IV. Chlorogenic acid in the leaves of Nicotiana tabacum. Physiol. Plant. 8, 594.

WeAving, A. S. (1958). Methods of determining chlorogenic acid in tobacco. Chem. \& Ind. p. 216.

YARwood, C. E. (1955). Mechanical transmission of an apple mosaic virus. Hilgardia, 23, 613. 